www.jmscr.igmpublication.org

Index Copernicus Value: 79.54

ISSN (e)-2347-176x ISSN (p) 2455-0450

crossrefDOI: https://dx.doi.org/10.18535/jmscr/v7i2.164

\title{
Quality of Life in Symptomatic and Asymptomatic Patients after Laparoscopic Cholecystectomy
}

\author{
Authors \\ Rajanala Madhu ${ }^{1}$, Sharvani Duba ${ }^{2}$, T J Prasanna Kumar ${ }^{3}$, V Sai Tejaswini ${ }^{4}$ \\ General Surgery Department, NRI General Hospital, Mangalagiri, Guntur District Andhra Pradesh, 522503, \\ India \\ Email: rajanalamadhu1@gmail.com
}

\begin{abstract}
Gallbladder diseases are very common in developed countries. Complicated gallstone disease represents the most frequent cause of biliary disorders for which surgery is regularly advocated. As regards, cholecystectomy represents a common abdominal surgical intervention; it can be performed as either an elective or emergency surgery, as in cases of gangrene, perforation or sepsis. Laparoscopic approach is considered GOLD STANDARD in recent times. There are numerous cholecystectomies being performed around the world on a daily basis. However, little evidence exists regarding assessment of post surgical quality of life (QOL) following these interventions. To assess post-cholecystectomy QOL, infact, documentation of high quality care has been subjected to extended discussions, and the use of patient reported outcome satisfaction for quality improvement has been little research published regarding QOL outcomes following cholecystectomy. Although several tools have been used to measure QOL after cholecystectomy, difficulty remains in selecting meaningful parameters. The aim of the study is to measure the quality of life, and dynamics of changes of individual components (physical, mental, social, and environmental), in patients undergoing cholecystectomy with post op follow up period ranging from 2 months post op to 6 months post op.

Materials and Methods: This is a prospective observational study carried out from august 2016 to august 2018. The study included patients treated for cholelithiasis by laparoscopic cholecystectomy at Department of General Surgery, NRI General Hospital, Chinakakani.
\end{abstract}

\section{Introduction}

Cholelithiasis involves the presence of gallstones, composed of cholesterol, bilirubin, calcium salts and other ingredients that form in the biliary tract. Symptomatic cholelithiasis requires surgical intervention. Mere presence of gallstones is not an indication for surgery. Today cholecystectomy is a standard practice for symptomatic cholelithiasis. It has a significant impact on Quality of life (QOL) in developed countries ${ }^{[1]}$. Nearly half the world population above 60 years age has gallstones, but only a small part suffers from pain related to the condition. Cholecystectomy for asymptomatic gallstones is often indicated in patients with diabetes, cardiac transplant recipients, oncologic patients and ones who require immunosuppressive and cytostatic therapy. ${ }^{[1-3]}$. 
There is a difference in presentation of cholecystitis in elderly and children. Elderly, present with vague symptoms without many important historicalor physical findings like pain or fever. Localized tenderness may be the only presenting sign; may progress to complicated cholecystitis rapidly. Children, present without many of the classical findings; those at higher risk include those suffering from, sickle cell disease, hemolytic conditions, need of prolonged total parenteral nutrition (TPN) or congenital biliary anomalies.

\section{Diagnosis}

Routine laboratory tests are not always reliable, but the following finding may be observed: leukocytosis with a left shift may be observed, alanine aminotransferase (ALT) and aspartate amintransferase (AST) levels may be elevated in cholecystitis or with common bile duct obstruction (CBD), amylase/lipase assays are used to assess for pancreatitis; they may be mildly elevated in cholecystitis. All females of childbearing age should undergo pregnancy testing. Diagnostic imaging methods like, Radiography, ultrasonography, computed tomography (CT), magnetic resonance imaging (MRI), hepatobiliary scintigraphy, endoscopic retrograde cholangiopancreatography (ERCP) may be considered.

While choosing a method of treatment, we must pay attention towards minimal interference to the function and efficiency of the patient and to restore the body to its original state of health. Quality of life and patient satisfaction following a surgery is an important factor in predicting treatment outcomes. Quality of life, as easy as it may sound to understand, has never been easy to define. In medicine we evaluate quality of life based on health related factors, and the approach determines the impact of the disease in physical, psychological and social aspects of life and well being $^{[2]}$. To fully assess a patient's quality of life we need to determine one's mood, physical and mental health and social functioning. Anxiety accompanies human beings throughout their lives and it is defined as a negative emotion connected with the anticipation of danger coming from outside or inside the body.

Anxiety is fear of anticipated threats, unpleasant for an individual. It is a negative emotion included by a factor subjectively considered as threatening [4-6]. Symptoms of anxiety are divided into physiological psychological and behavioural. In medical literature there are no studies on the levels of anxiety in patients treated surgically for cholelithiasis $^{[6,7]}$.

\section{Aims}

Assessment of quality of life in all its components (physical, mental, social, environmental) in patients who underwent cholecystectomy, for symptomatic and asymptomatic gall stone disease. To understand whether surgery was beneficial to asymptomatic patients' or not.

Evaluating the factors that may affect quality of life, and the treatment effect, in the period of time which was the subject of analysis.

\section{Materials and Methods}

This prospective observational study was conducted in two years. The study group consisted of 151 patients who underwent cholecystectomy. 136 were enrolled for research analysis, including 98 women, 38 men between age 18 to 70 years .15 patients were excluded from the study. The study included patients treated at Department of General Surgery , NRI General Hospital, Chinakakani. 76 had previous attack of acute cholecystitis or biliary colic, 36 presented with complications and in 26 gallstones were diagnosed as an incidental finding on USG abdomen who were evaluated for other abdominal conditions. Patients with metabolic disorders (diabetes, obesity, hypercholesterolemia) were included. The analysis excluded patients with chronic diseases (stomach and bowel disorders, gallbladder cancer, other cancers, mental illness), pregnant women and in whom laparoscopy is converted to conventionl open approach. Tests 


\section{JMSCR Vol||07||Issue ||02||Page 944-950||February}

were carried out before surgery, two weeks after, one month after, 6 months after and 12 months after surgery. Minimum follow up period was for 12 months and maximum was for 24 months. The data obtained from the WORLD HEALTH ORGANIZATION QUALITY OF LIFE QUESTIONNAIRE WHOQOL BREF [TABLE 2]. Calculations included mean values, standard deviations, and medians of studied parameters. The normality of the distribution was evaluated with Kolmogorov -Smirnov test. In the case of normal distributions, the student's t-test was used for comparison between groups. In order to compare the results between time points the Wilcoxon test was used. The frequency of the studied traits was calculated. The statistical significance level was $\mathrm{p}<0.05$.

The WHOQOL questionnaire helps in obtaining a profile of the quality of life in four areas (physical, psychological, social relationships, and environment). The scores reflect the individual's perception of the quality of life in these four areas. The greater the number on scale, the better quality of life. The quaetionnaire includes 26 questions.

Table 1: Characteristics of patients

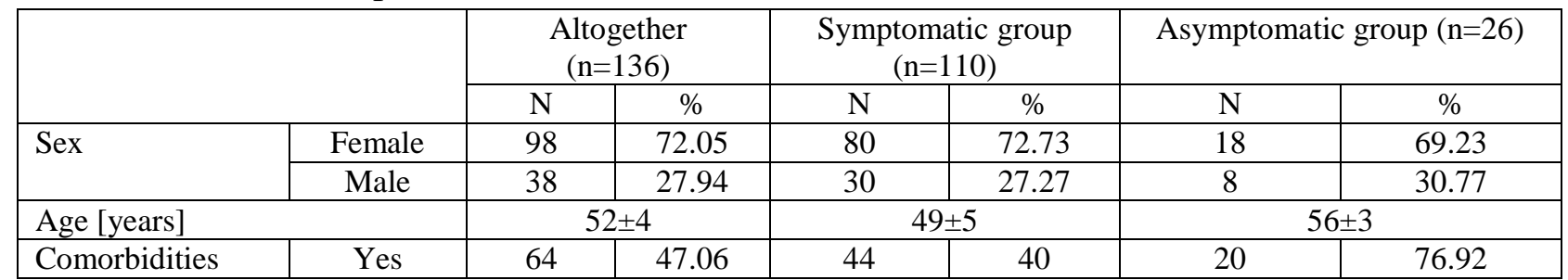

Table II: World Health Organization Quality of Life questionnaire WHOQOL

\begin{tabular}{|c|c|c|c|c|}
\hline \multicolumn{5}{|c|}{ 1. How satisfied are you with the quality of your life? } \\
\hline Very dissatisfied & Dissatisfied & $\begin{array}{l}\text { Neither satisfied nor } \\
\text { dissatisfied }\end{array}$ & Satisfied & Very satisfied \\
\hline \multicolumn{5}{|c|}{ 2. How happy you are for your health? } \\
\hline Very dissatisfied & Dissatisfied & $\begin{array}{l}\text { Neither satisfied nor } \\
\text { dissatisfied }\end{array}$ & Satisfied & Very satisfied \\
\hline \multicolumn{5}{|c|}{$\begin{array}{l}\text { The following questions relate to what extent or how you felt certain things in the past } 2 \text { weeks. } \\
3 \text {. To what extent do you feel that physical pain restricts you in doing what you want? }\end{array}$} \\
\hline At all & Little & Quite strongly & Very strongly & Extremely strongly \\
\hline \multicolumn{5}{|c|}{ 4. To what extent lead a normal, everyday life depend on any treatment? } \\
\hline At all & Little & Quite strongly & Very strongly & Extremely strongly \\
\hline \multicolumn{5}{|c|}{ 5. How much do you enjoy life? } \\
\hline At all & Little & Quite strongly & Very strongly & Extremely strongly \\
\hline \multicolumn{5}{|c|}{ 6. To what extent do you feel that your life has meaning, significance? } \\
\hline At all & Little & Quite strongly & Very strongly & Extremely strongly \\
\hline \multicolumn{5}{|c|}{ 7. How easily can you focus on? } \\
\hline At all & Little & Quite easy & Very easy & Extremely easy \\
\hline \multicolumn{5}{|c|}{ 8. Do you feel safe in your daily life? } \\
\hline At all & Little & Average & Very sate & Extremely safe \\
\hline \multicolumn{5}{|c|}{ 9. How healthy you feel the area in which you live? } \\
\hline At all & Little health & Quite healthy & Very healthy & Extremely healthy \\
\hline \multicolumn{5}{|c|}{$\begin{array}{l}\text { The following questions relate to the extent to which you were able to perform things in the past } 2 \text { weeks. } \\
\text { 10. Do you have enough forces - "energy" to lead a normal life? }\end{array}$} \\
\hline At all & Little & Average & Almost enough & Enough \\
\hline \multicolumn{5}{|c|}{ 11. Are you able to accept your appearance? } \\
\hline At all & Little & Average & Mostly & Completely \\
\hline \multicolumn{5}{|c|}{ 12. Do you have enough money for Your needs? } \\
\hline At all & Little & Average & Almost enough & Enough \\
\hline \multicolumn{5}{|c|}{ 13. To what extent are available to you the information you need for everyday life? } \\
\hline At all & Little & Average & Mostly & Completely \\
\hline \multicolumn{5}{|c|}{ 14. To what extent you have the possibility of such leisure activities as you wanted to? } \\
\hline At all & Little & Average & Almost enough & Enough \\
\hline
\end{tabular}


15. To what extent can you move?

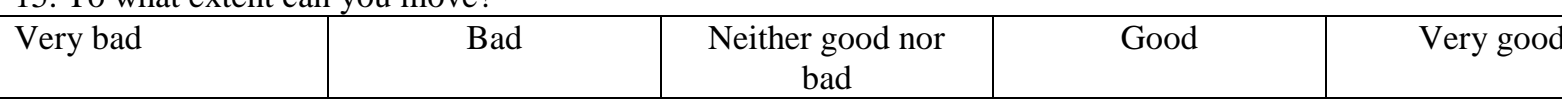

The following questions relate to how satisfied and happy you felt in relation to the various spheres of life in the past

2 weeks.

16. How satisfied are you with your sleep?

\begin{tabular}{|l|c|c|c|c|}
\hline Very dissatisfied & Dissatisfied & $\begin{array}{c}\text { Neither good nor } \\
\text { bad }\end{array}$ & Satisfied & Very satisfied \\
\hline
\end{tabular}

17. How satisfied are you with their ability to lead a normal daily life?

\begin{tabular}{|l|c|c|c|c|}
\hline Very dissatisfied & Dissatisfied & $\begin{array}{c}\text { Neither satisfied nor } \\
\text { dissatisfied }\end{array}$ & Satisfied & Very satisfied \\
\hline
\end{tabular}

18. How satisfied are you with your ability to work (paid or unpaid, at home)?

\begin{tabular}{|l|c|c|c|c|}
\hline Very dissatisfied & Dissatisfied & $\begin{array}{c}\text { Neither satisfied nor } \\
\text { dissatisfied }\end{array}$ & Satisfied & Very satisfied \\
\hline
\end{tabular}

19. How satisfied are you with yourself?

\begin{tabular}{|l|c|c|c|c|}
\hline Very dissatisfied & Dissatisfied & $\begin{array}{c}\text { Neither satisfied nor } \\
\text { dissatisfied }\end{array}$ & Satisfied & Very satisfied \\
\hline $20.40 w$
\end{tabular}

20. How satisfied are you with your personal relationships?

\begin{tabular}{|l|c|c|c|c|}
\hline Very dissatisfied & Dissatisfied & $\begin{array}{c}\text { Neither satisfied nor } \\
\text { dissatisfied }\end{array}$ & Satisfied & Very satisfied \\
\hline
\end{tabular}

21. How satisfied are you with your sex life?

\begin{tabular}{|l|c|c|c|c|}
\hline Very dissatisfied & Dissatisfied & $\begin{array}{c}\text { Neither satisfied nor } \\
\text { dissatisfied }\end{array}$ & Satisfied & Very satisfied \\
\hline
\end{tabular}

22. How satisfied are you with the support you receive from your friends?

\begin{tabular}{|l|c|c|c|c|}
\hline Very dissatisfied & Dissatisfied & $\begin{array}{c}\text { Neither satisfied nor } \\
\text { dissatisfied }\end{array}$ & Satisfied & Very satisfied \\
\hline
\end{tabular}

23. How satisfied are you with the conditions in which you live?

\begin{tabular}{|l|c|c|c|c|}
\hline Very dissatisfied & Dissatisfied & $\begin{array}{c}\text { Neither satisfied nor } \\
\text { dissatisfied }\end{array}$ & Satisfied & Very satisfied \\
\hline
\end{tabular}

24. How satisfied are you with access to medical care?

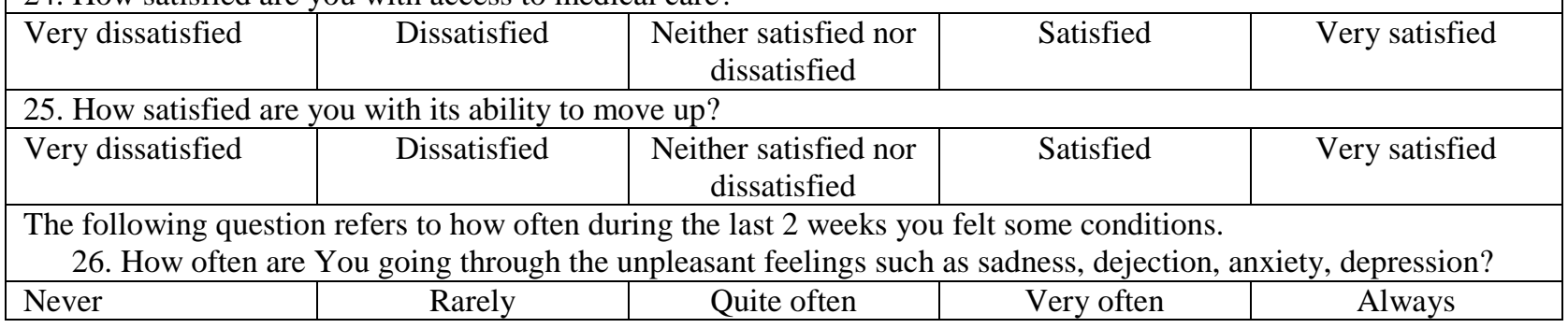

Table III: Quality of Life questionnaire WHOQOL

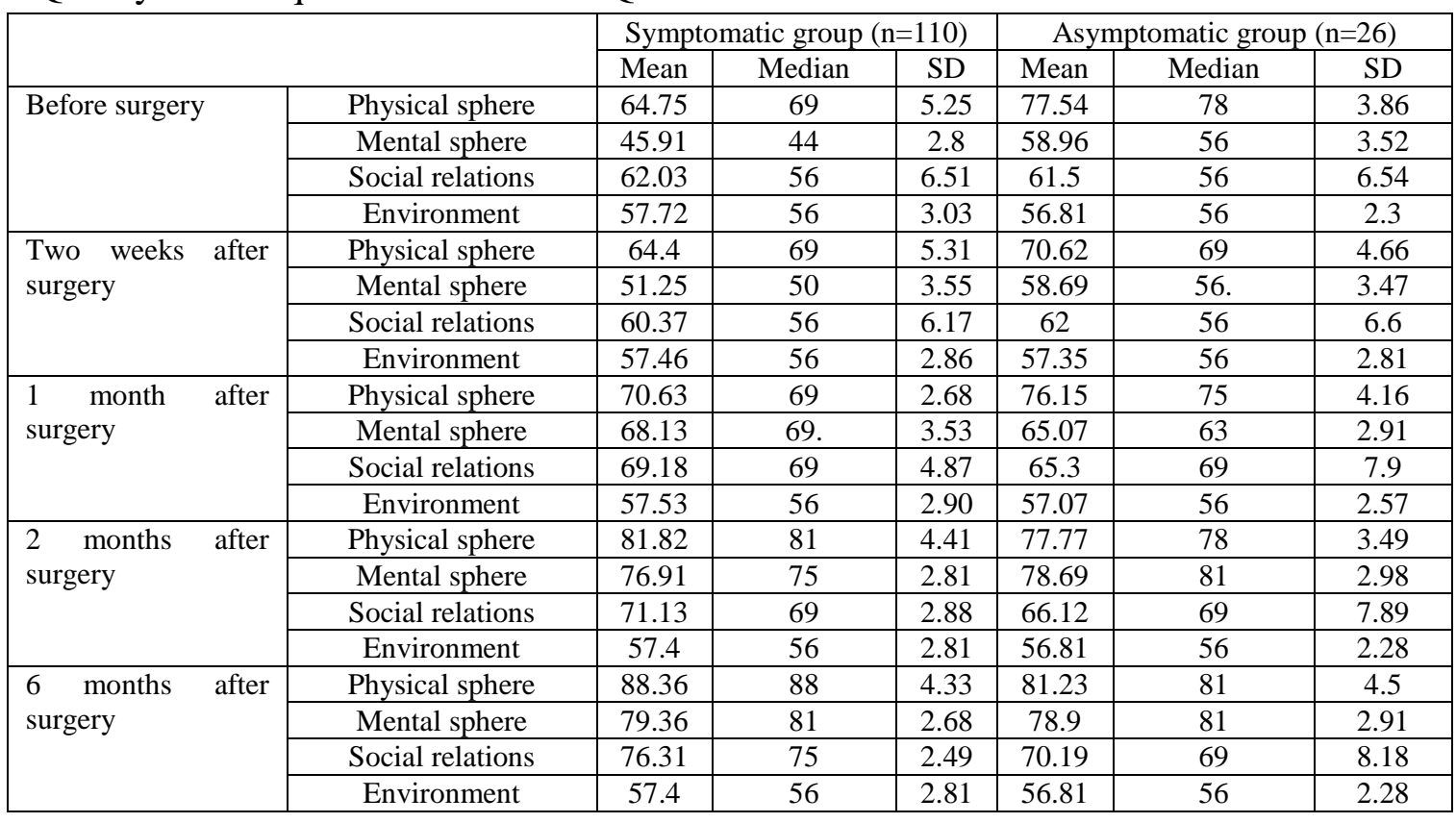


Table IV: Comparison of results

\begin{tabular}{|l|l|c|c|}
\hline & & Symptomatic group & Asymptomatic group \\
\hline \multirow{4}{*}{ Physical sphere } & Before \& 2 weeks after surgery & 0.6283 & $<0.0001$ \\
\cline { 2 - 4 } & Before \& 1 month after surgey & $<0.0001$ & $0.2841(\mathrm{NS})$ \\
\cline { 2 - 4 } & Before\&2 months after surgery & $<0.0001$ & $0.6888(\mathrm{NS})$ \\
\cline { 2 - 4 } & Before\&6 months after surgery & $<0.0001$ & 0.026 \\
\hline \multirow{5}{*}{ Mental sphere } & Before \& 2 weeks after surgery & $<0.0001$ & 0.7827 \\
\cline { 2 - 4 } & Before \& 1 month after surgey & $<0.0001$ & $<0.0001$ \\
\cline { 2 - 4 } & Before\&2 months after surgery & $<0.0001$ & $<0.0001$ \\
\cline { 2 - 4 } Social sphere & Before\&6 months after surgery & $<0.0001$ & $0.7852(\mathrm{NS})$ \\
\hline \multirow{5}{*}{ Environmental sphere } & Before \& 2 weeks after surgery & $0.0543(\mathrm{NS})$ & $0.0625(\mathrm{NS})$ \\
\cline { 2 - 4 } & Before \& 1 month after surgey & $<0.0001$ & $0.0260(\mathrm{NS})$ \\
\cline { 2 - 4 } & Before\&2 months after surgery & $<0.0001$ & 0.0001 \\
\cline { 2 - 4 } & Before\&6 months after surgery & $<0.0001$ & $\mathrm{NS}$ \\
\cline { 2 - 4 } & Before \& 2 weeks after surgery & $\mathrm{NS}$ & $\mathrm{NS}$ \\
\cline { 2 - 4 } & Before \& 1 month after surgey & $\mathrm{NS}$ & $\mathrm{NS}$ \\
\cline { 2 - 4 } & Before\&2 months after surgery & $\mathrm{NS}$ & $\mathrm{NS}$ \\
\hline
\end{tabular}

\section{Results}

The patients treated by surgery declared higher quality of life during the overall follow up period. All symptomatic patients were initially treated with parentral and oral medication to prevent complications \& to resolve the inflmmatory/ infective process. 4 to 6 weeks after the acute stage patients were advised to come for laparoscopic cholecystectomy. In the period of 4 to 6 weeks, many paid visit to the outpatient department; minimum 2 visits, with complaints of persistence of gastrointestinal symptoms and pain in the right hypochondrium. However, on examination there were no findings suggestive of acute chcolecystitis; such patients were reassured and less often oral analgesia was advised. In this study there was a statistically significant difference in the quality of life of patients who experienced acute attack before the surgery. The difference observed before and after the surgery in the areas of physical, mental and social characteristics was favourable to patients who were previously symptomatic. The difference observed before and after the surgery in areas of mental characteristics was significant in asymptomatic group. Table 4 presents the results of the questionnaire WHOQOL-BREF, evaluating quality of life. Patients treated by laparoscopic cholecystectomy in asymptomatic group have shown decrease in physical quality of life 2 weeks after surgery. This can be attributed to port site pain and not to any other gall bladder disease related complications.

\section{Discussion}

There is concern about the risk of inappropriately selecting patients with functional gastrointestinal symptoms for cholecystectomy ${ }^{[8}$. there has always been a difference in opinion regarding the beneficial effects of cholecystectomy in asymptomatic patients., in which case, if the baseline health status of people with gallstones is equal to that of general population, there should be no difference between operated and non operated patients. A study performed by Mentes et al. suggested that laparoscopic surgery should also be performed on asymptomatic patients since this group improved in their gastrointestinal quality of life (GIQLI) score. The general consensus amongst most authors, however seems to be that this group should not be treated surgically. ${ }^{[9,10]}$ Several studies have been performed comparing quality of life before and after a surgical procedure. However, it may be difficult to determine if improvement in health related quality of life seen after surgery is a result of the surgical intervention per se, or it is mainly a placebo effect? The study shows that the patients who underwent surgery for previously being symptomatic or asymptomatic have higher quality of life upto 1 
year only after that they feel no difference. This can be attributed to lesser psychological stress once they know the causative factor has been removed. The lesser occurrence of post cholecystectomy syndrome in is also significant. Budzynski notes that the quality of life of patients after laparoscopic cholecystectomy improves sooner than after classical surgery. The development of laparoscopy changed the entire outlook of cholecystitis and cholelithiasis. The number of complications and mortality rates have been greatly reduced due to the implementation of laparoscopic technique. Higher satisfaction rate for surgical scars after surgery has also been confirmed $^{[11]}$. Matovic confirms the results implying that the quality of life in patients treated laparoscopic method is higher compared to those treated by open method. Fitness, emotional state, and social activity are much better in patients treated by laparoscopic cholecystectomy ${ }^{[12]}$. Topcy and Karakaya studied the patients quality of life for more than 3 years after surgery, concluding that there was better quality of life in laparoscopic cholecystectomy than open method. ${ }^{[13]}$. Rasanen assesses the quality of life after 4,6,12 months of surgery, stating that an increase was observed in just 4 months. This shows that to assess the full effect of gastroenterological surgery by measuring quality of life we need 12 months. ${ }^{[14]}$

\section{Conclusion}

Gallstone disease has a profoundly negative impact on quality of life, especially in symptomatic patients with a history of biliary colic attacks and/or the complications of the disease. Although the condition is not equally distressing for the asymptomatic group of patients, In both symptomatic and asymptomatic group better quality of life scores were seen with laparoscopic cholecystectomy.

Post cholecystectomy (PC) symptoms were less commonly noted in patients treated with laparoscopic method. The symptoms of PC were more in women than in men. It can also be emphasized that there is worldwide acceptance of the fact that asymptomatic gallstones, infact, should not be treated. ${ }^{[15]}$

In conclusion, although sensitive and responsive instruments for the measurement of postcholecystectomy Quality of life exsist more research is needed to identify modifications that could lead to significant improvements.

\section{Acknowledgement}

Department of preventive and social medicine for their immense help in statistics. Department of radiology for their help in diagnosing the cases.

\section{References}

1. Russo MW, Wej J T, Thiny MT, Gangarosa LM, Brown A, Ringel Y, Shaheen NJ, Sandler RS. Digestive and liver diseases statistics, . Gastroenterology 2004; 126:1448-1453.

2. Krawczyk M (2005) Gallbladder and bile ducts. W: Noszczyk W (red) Sugery Warsaw: PZWT 821-838.

3. Sakorafas GH, Milingos D, Peros G. Asymptomatic cholelithiasis: is cholecystectomy really needed? A critical reappraisal 15 years after introduction of laparoscopic cholecystectomy. Dig Dis Sci.2007;52(5) 1313-1325.

4. Kasaka L, Sledzinski Z, Kobiela J (2006) Quality of life after laparoscopic and open surgery. Videosurgery 2:77-86.

5. Caumo W Schmidt AP, Schineider CN, Bergmann J, Iwamoto CW, et al (2001) risk factors for preoperative anxiety in adults. Acta Anaesthesiol Scandd 45: 298307.

6. Romanik W, Kanski A, Soluch P (2009) questionnaires and declarative level of anxiety of patients before surgery. Anaesthesiology and intensive care XLI 2: 94-99.

7. Kaluzynski M, Kocur J (2004) The level of anxiety as a state of characteristics of 
patients with ischemic heart disease or hypertension. The Art of Therapy 10:23-29.

8. K.borsch, K.jonsson, J.M. Zdolsek, I. Halldestam, and E.Kullman, "Prevalence of gallstone disease in a Swedish population samle: relations to occupation, childbirth, health status, lifestyle, medications, and blood lipids," Scandinavian journal of gastroenterology, vol 33,no. 11,pp.1219-1225,1998.

9. B.B. Mentes, M. Akin O. Irkorucu et al., "Gastrointestina quality of life in patients with symptomatic or asymptomatic cholelithiasis before and after laparoscopic cholecystectomy," British journal of surgery, vol.90, no.12, pp.1549-1555.

10. P.W. Plaisier, "comment on gastrointestinal quality of life in patients with symptomatic and asymptomatic cholelithiasis before and after laparoscopic cholecystectomy," surgical endoscopy, vol. 17,p.169,2003

11. Carraro A, Dania EI, Florian B (2011) Healt-related quality of life outcomes after cholecystectomy. World gastroenterol. 17:4945-4951.

12. Matovic E, Hasukic S, Ljuca F, Halolovic H (2012) Quality of life in patients after laparosopic and open cholecystectomy. Med Arh66 :97-100.

13. Topcy O, Karakayali F, Kuzu MA, Ozdemir S, Erverdi N, et al.(2003) Comparison of long term quality of life after laparoscopic and open cholecystectomy. Surg Endosc 17: 291-295.

14. Rasanen JV, Niskanen MM, Miettinen P, Sintonen H, Alhava E et al. (2001) Health related quality of life before and after gastrointestinal surgery.Eur J Surg 167: 419-425

15. National institutes of health concensus conference (1993) Gallstones and laparoscopic cholecystectomy. J Am Med Assoc 269:1018-1024. 